\title{
The Use Of Binary And Ternary Paradoxes In Management
}

\author{
Charles J. Capps, III, Sam Houston State University, USA
}

\begin{abstract}
Conventional reality, or "reality by convention," as portrayed by today's corporate mainstream media, is revisited with alternative explanations proposed. Contrived Binary and Ternary Paradoxes are presented as unethical examples of duplicity that mislead and deceive consumers.
\end{abstract}

Keywords: Social responsibility, corporate ethics, consumer decision-making, and oligopolies

\section{INTRODUCTION}

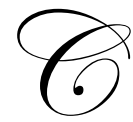

how (1988) stated, "The magnitude of the experimental effect is treated in a binary manner, even though it numerically is a continuous variable." He even questioned whether statistical analyses could tell us anything other than "Yes, you should continue to support this theory," or "No, you should not continue to support this theory." Similarly, Folger (1989) proposed the "duplicity of binary decisions," and he labeled duplicity as "an attempt to dupe the unsuspecting." When both alternatives actually represent the same interests, are not "Binary Paradoxes" simply being used to mislead consumers by disguising choices? Further, is it possible there is also a contrived "Ternary Paradox?" It is possible that the magnitude of the experimental effect may be neither a continuous variable nor a binary determination because a choice may not actually exist. For a consumer, there may be only the illusion of having a choice.

The duplicitous Binary Paradox is somewhat like a Hobson's choice, a situation in which one may prefer to avoid both possible undesirable consequences. In a Hobson scenario, a man who does not know how to swim is floating on a burning raft in the middle of the ocean. Either option, to stay or not, is disastrous. Similarly, when both options (choices) are owned by the same disguised interest, does a true choice really exist? The Binary Paradox offers two alternative choices that are simply controlled by the same or related disguised interest. It is much like the casino that does not care what color the roulette players select (red or black) as long as the customers continue to play and the house prospers. Ultimately, the real winner is always the corporate casino owner who spins the wheel.

In the marketplace, do consumers always have a choice, or are some binary decisions simply a deceptive illusion like a Don King prizefight? Does not the decision to transact business with monopolistic interest disguised as two different choices represent a Binary Paradox? Therefore, the "Binary Paradox" is defined as that duplicitous state where "no real choice" exists because both selections are provided by the same or related interest. This paper presents the use of this type of duplicity to influence the consumers' decision-making process. The restriction of "either/or" and "left/right" binary decisions, or "false choices," is cited. Then, the likelihood of deceit affecting consumer decision-making is expanded to ternary decisions. Finally, a critique of the ethical implications of these dishonest practices is offered.

Conceptually, the hypothetical likelihood for duplicity influencing a consumer's decision is probably the result of the amount of money involved and the number of choices available to the decision-maker. Mathematically, the theoretical probability for duplicity is likely a function where $d=f(\$ n)$, and $n$ is the number of choices, or companies, involved. The motivation for not informing, misinforming and deceiving is likely increased revenue, particularly for powerful interlocked multinational oligopolies. The dollar sign $\$$ represents this amount. In a true monopoly, $\mathrm{n}$ always equals 1 . With a binary decision, $\mathrm{n}$ is equal to 2 . A ternary decision has an $\mathrm{n}$ of 3 , etc. Logic suggests when $n=1$, there is often less need to disguise the duplicity; when $n=2$, there is a greater need to hide the 
deception; and, when $n=3$, even more calculated deceit is required to successfully camouflage and obscure the truth.

The "Ternary Paradox" is defined as that duplicitous state where "no real choice" exists because all three possible choices are owned by similar or related interest. The Ternary Paradox is really an expanded version of the false choice Binary Paradox; however, the Ternary Paradox differs because it contains the illusion of three choices, which the consumer cannot see through. The Ternary Paradox's false choice approach is just a slight variation of the Binary Paradox's duplicity, which is expanded to three disguised possibilities that are intended to further confuse and swindle consumers.

Now responding to Chow's (1988) two basic questions (i.e., "Yes, you should continue to support this theory," or "No, you should not continue to support this theory"), this perspective suggests "reality by convention" is often created and heavily influenced by the global establishment's corporate mainstream media using false choice contrived Binary and Ternary Paradoxes to hide the interests of international oligopolies from the masses. It seems multinational corporate (MNCs) powers do indeed control nation states, even "shadowing" the United States of America. It appears the USA is changing from a nation-state to a corporate-state where profits supersede the rights of individuals and allow corporatism and fascism to grow.

\section{CONCLUSION}

In conclusion, we revisit the question of whether customers always have a choice, or are some consumer decisions intentionally a deceptive illusion. The influences of MNCs certainly allow hiding the fact that only a few powerful established companies control most consumer choices. If ethics and social responsibility are important in our society, then it seems honesty in advertising should require multinational corporate manufacturer's to label their products so informed buyers may add that factor to their consumer decision-making process. Consumers ethically deserve the truth before casting their economic vote in the marketplace. The consumer has a right to know before they consume something that may be very counter to their core values.

\section{AUTHOR INFORMATION}

Dr. Charles J. Capps III, SPHR, is professor of management at Sam Houston State University where he teaches strategy and human resource management. He is a lifetime certified Senior Professional in Human Resources. Dr. Capps' industry experience as a human resource development (HRD) practitioner includes establishing and managing a large petrochemical training program where the world's record in safety was set. As a consultant, Dr. Capps trained hundreds of law enforcement professionals in strategic management for the Law Enforcement Management Institute of Texas (LEMIT). In addition, Dr. Capps has provided management and human relations training to national and international corporations.

\section{REFERENCES}

1. Chow, Sui. L., (January 1988). Significance test or effect size? Psychological Bulletin, Volume103, Number 1, pages 105-110.

2. Folger, Robert, (January 1989). Significance tests and the duplicity of binary decisions, Psychological Bulletin, Volume 106, Number 1, pages 155-160. 